\title{
Smart Health Advisory System Using IoT
}

\author{
Debnath Bhattacharyya1)
}

\begin{abstract}
The Internet of Things (IoT) gives Associate in nursing temperate and new life to the human services field. It conjointly incorporates a quick advancement of the many fields. However a ton of fundamental necessities are existing for human wellbeing inside the field of Medical. One among the higher approach the specialists are skilled to and rapidly appropriate to utilize the pertinent patient data's and together with the patient case history. Through the net of Things, staggeringly enhances the standard of information and in this way the patient care inside the Medical field. Along these lines, web of Things offers Associate in Nursing real stage to interconnect the every one of the assets. Relate in nursing metaphysics based for the most part computerizing style procedure for good medications and physical wellbeing framework abuse IoT. Semantics and metaphysics components helps the PCs notwithstanding the understanding the indications and restorative assets. In this way, cosmology instrument makes a recovery methodology and reconfigure medicinal assets steady with patient's particular necessities apace and more than once.
\end{abstract}

Keywords : IoT, Health data, Ontology, Worldwide ontology, Knowledge base, Patient data, Output prescription

\section{Introduction}

Internet of Things (IoT) gadgets will be basically acclimated encourage far off wellbeing viewing and crisis mind frameworks[1][2]. At this we tend to confront a few difficulties inside the universe that should bargain practically. By the use of IoT challenges square measure restore, that devours longer, assets and work constrain[3]. Inside the current years the restoration of web assets has turned out to be normal and also advancement of the sensible applications like sensible home[4]. Contrasted with the standard framework, the sensible recovery is going for giving a decent treatment, sufficient collaboration and quick reconfiguration to making the decided utilization of the therapeutic assets reliable with the patient's unequivocal needs plausible. Web of Things is that the essential innovation for

Received(May 10, 2018), Review Result(1st: May 23, 2018, 2nd: June 20, 2018), Accepted(June 25, 2018)

${ }^{1}$ Department of Computer Science and Engineering, Vignan's Institute of Information Technology, Visakhapatnam, AP, India

email: debnathb@gmail.com 
interconnecting all the restorative assets of the recovery frameworks. Also to blend the Networking advancements that permits a decent shift of utilizations, gadgets or things to act and convey among themselves.

The Internet of Things (IoT) is a game plan of consistent get ready contraptions, automatic and electronic machines, things, animals or people that are outfitted with unique identifiers and the ability to trade data over a framework without anticipating that human-should human or human-to-PC correspondence[5]. IoT has progressed from the meeting of remote developments, scaled down scale electromechanical systems (MEMS), littler scale organizations and the web. Kevin Ashton, prime supporter and authority official of the Auto-ID Center at MIT, first indicated the Internet of Things in an acquaintance he made with Procter and Gamble in 1999[6][7]. About most of the around 50 petabytes (a petabyte is 1,024 terabytes) of data open on the web were first gotten and made by individuals by composing, crushing a record find, taking an electronic picture or checking an institutionalized recognizable proof[8].

The issue is that the general population has obliged time, thought and exactness - all of which recommends they are terrible at getting information about things really. On the off chance that we had PCs that knew everything there was to consider things - utilizing information they accumulated with no assistance from us - we would be able to track and check everything and incredibly decrease waste, mishap and cost. We would know when things required supplanting, repairing or keeping an eye on and whether they were new or past their best." IPv6's enormous expansion in address space is a basic factor in the difference in the Internet of Things. An improvement in the measure of keen focuses, and besides the measure of upstream information the inside focuses make, is relied on to raise new worries over information protection, information power and security.

Helpful jobs of IoT advancement can be found in different ventures today, including exactness developing, building association, human organizations, vitality and transportation. Openness choices for contraptions specialists and application makers wearing out things and frameworks for the Internet of Things. Neglecting how the contemplation wasn't named until 1999, the Internet of Things has been being made for a noteworthy long time. Web of Things (IoT) has a few assortments of employments together with mind and present day frameworks. Along these lines, mind structures fundamentally misuse the interconnected gadgets to shape relate degree IoT deal with exceptional to appraisal, mechanically sleuthing things and screens the patients, wherever the therapeutic impedances square measure urgent. Thusly, IoT alone will kind assistant degree information deal with that interconnects patching workplaces, society, mind gadgets, home air and varying workstations[9][10]. 


\section{Usage}

Usage of the net of Things is adaptable and open outcomes to allowing the care applications to serve patients with higher treatment, moreover through with the remote patient viewing and viable medicinal data dealing with. There square measure various totally extraordinary qualities square measure required to actualize the care benefit inside the climate.

\section{1) Ontology Assessment}

In this half data sources are recover into work amid which patients side effects are examined, illnesses are settled, and each one the data's are put into the remote data. Once the patient introductory enters the doctor's facilities, the physical attributes of the illnesses will be principally controlled by the specialist. The decided capacities are separated into the classifications and sub classifications. Classes speak to the patient's essential information and subclasses speak to explained sicknesses information.

\section{2) Universal Ontology Evaluation}

In this assessed metaphysics demonstrate contrasted with the all around hang on illnesses different ontologies on the base of the mental question framework. World philosophy bunches contains the 2 assortments of cosmology, these are ailment metaphysics and asset philosophy. Sickness metaphysics contains the patient fundamental and restorative information and asset cosmology covers medicinal assets determined specialists, therapeutic gadgets, and so on.

\section{3) Resemblance Calculations}

Info the request substance of the side effect physically. Contrast the information side effect and all the overall illness transcendentalism among the substance. Perform similitude coordinating of the side effects naturally for comparability coordinating. Adjust the determination of the premier comparable case among the substance. It's anything but difficult to chase out what styles of gadgets territory unit required for the comparing side effects and restoration courses through the philosophy. 


\section{4) Designed Model Optimization:}

The last area of good style technique amid which the methodology, strategies, degrees, and length of the greater part of the different activities. Parameter enhancement is vital to make guaranteed that the particulars experience the needs from structure. Programmed styles encourage to make a framework wherever a substitution patient might be immediately analyzed, comparing encourage methodology will after a short time be found, and related therapeutic properties will be appropriated amid a brief timeframe. With metaphysics influencing certain the customary information to structure.

\section{Proposed System}

In anticipated framework relate philosophy principally based mechanizing style procedure for sensible solution and physical wellbeing framework abuse IoT. Notwithstanding handle the indications and along these lines the medicinal resources by the usage of partner metaphysics. What's more, also relate metaphysics backings to shape a restoration technique and moreover to reconfigure the medicinal resources upheld the particular needs of the patients routinely and quickly. In this way, bolstered the goals IoT means to interconnect every one of the assets and just give quick information cooperation. Real part amid this framework is to applying the cosmology for the production of recovery procedure and to make the plan examinations for cooperation of the patients Informations or personality. The fundamental set up of IoT is that the inescapable nearness of things and items that unit of estimation interconnected and unit of estimation ready to get along the edge of each other to accomplish a run of the mill objective. IoT degrees a cluster of advancements that backings a comprehensive shift of things to act and interconnect among them work on systems administration innovations.

A couple of critical decisions, advance on the grounds that the speedy development of recovery framework and along these lines the direct sharing of space information, construct the framework particular and perform radiant, as IoT. Philosophy have fight a tremendous part at interims the procedure. It plans to interconnect every one of the assets and give prompt information collaboration. The fundamental set up of IoT is that the inescapable nearness of things and items that unit of estimation interconnected and unit of estimation ready to get along the edge of each other to accomplish a run of the mill objective. IoT degrees a cluster of advancements that backings a comprehensive shift of things to act and interconnect among them work on systems administration innovations. The fundamental set up of IoT is that the 
inescapable nearness of things and items that unit of estimation interconnected and unit of estimation ready to get along the edge of each other to accomplish a run of the mill objective. IoT degrees a cluster of advancements that backings a comprehensive shift of things to act and interconnect among themselves work on systems administration innovations.

For the usage of the anticipated framework ought to be have some of the different sort of the areas. First one is that the Human machine connection and second is multidisciplinary improvements that are made inside the few operations on the framework outline. What's more, third one is dealing with the applications by the information and modernity mapping inside the learning base. The Human machine communication is accomplished by the base of the assets and human, similar to specialists, attendant and patients square measure the human related assets and gadgets such the RFID, rescue vehicle, restorative assets square measure the demonstration to the HR. Second, Multidisciplinary improvements that is utilized to play out the look of the machine-controlled plan philosophy and hence the real part inside the framework outline. Because of it, it makes the all procedure of the framework and furthermore to supply the remedy to quiet mechanically.

Third, overseeing applications is utilized to deal with every one of the assets and furthermore the patient's records moreover. The patient's records moreover kept up by classes and sub classifications as clarified in execution. In application administration also plays out the arranging joint effort, information and application combination bolstered the data and in this manner the substance inside the framework. The Human machine communication is accomplished by the base of the assets and human, similar to specialists, attendant and patients square measure the human related assets and gadgets such the RFID, rescue vehicle, restorative assets square measure the demonstration to the HR. Second, Multidisciplinary improvements that is utilized to play out the look of the machine-controlled plan philosophy and hence the real part inside the framework outline. Because of it, it makes the all procedure of the framework and furthermore to supply the remedy to quiet mechanically. The Human machine communication is accomplished by the base of the assets and human, similar to specialists, attendant and patients square measure the human related assets and gadgets such the RFID, rescue vehicle, restorative assets square measure the demonstration to the HR. Second, Multidisciplinary improvements that is utilized to play out the look of the machine-controlled plan philosophy and hence the real part inside the framework outline. Because of it, it makes the all procedure of the framework and furthermore to supply the remedy to quiet mechanically. 


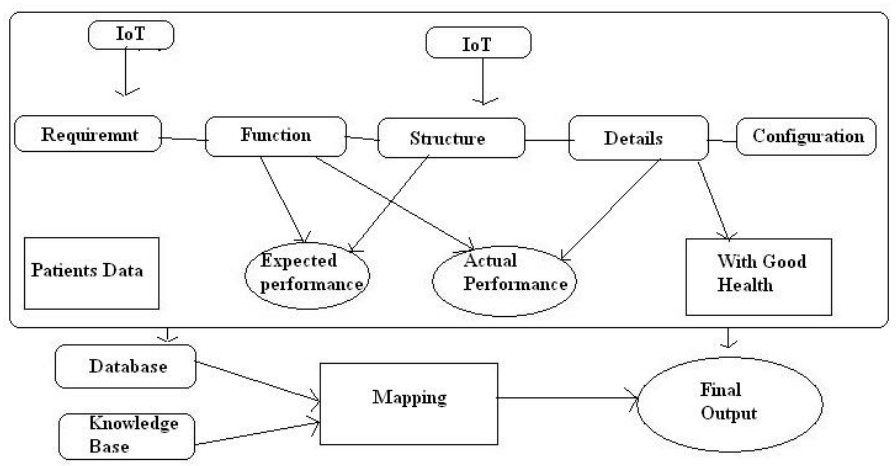

[Fig. 1] Architecture model of the proposed System

\subsection{Age of Robotized Plan}

The age of the automatize style procedure should be have some of the stages clarified inside the usage and associated works. Once the patient or specialists inputs the indications of the maladies, it is regularly contrasted with the world philosophy bolstered mental protest and picks their most comparable case inside the mental question. At the point when the programmed style system mapping to classifications and sub classes of the as of now keep patients records. Once the patient or specialists inputs the indications of the maladies, it is regularly contrasted with the world philosophy bolstered mental protest and picks their most comparable case inside the mental question. Once the enduring or expert inputs the suggestions of the maladies, it is regularly dissimilarity with the world attitude bolstered cerebral complaint and choose their most similar case within the cerebral query.

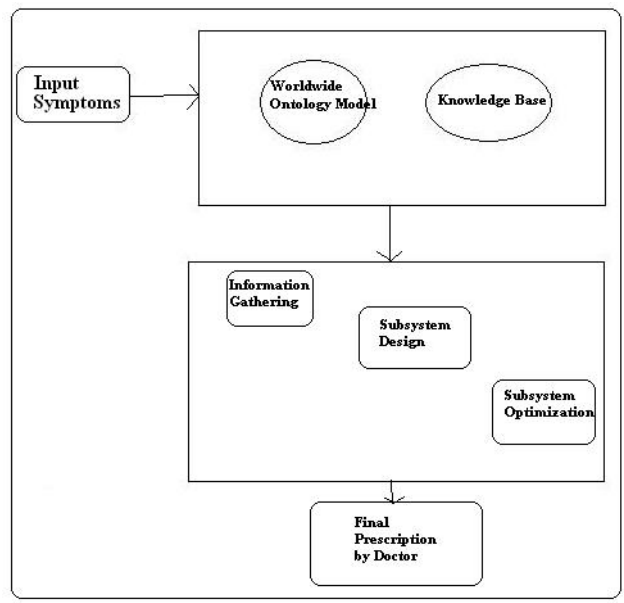

[Fig. 2] Data Generation model of the proposed System 
The present plan will enhance that the patient's records bolstered their maladies and essential information. At long last style coordinated effort will take significant part inside the style subject to supply the solution to the patient when confirmation of the specialists. By exploitation this method are regularly compelling to the medicinal and care frameworks.

\section{Results and Discussion}

The arranged outline of IoT based for the most part physical wellbeing framework which will be incorporated to the some recovery system by conglomeration the patient essential data's and indications and conjointly deals with the anamnesis. Framework discovers that right reconfiguration of the Medical assets will build up the execution of the framework and conjointly beyond any doubt patness to the patients. The usage of the medicinal assets ought to be utilized appropriately. Upheld the arranging of framework is powerful and might encourage to the sensible medications framework by creating the solution. By summoning the RFID to interconnection of the every one of the assets and move with the server all through the reconfiguration of the patients restorative assets and to supply arrangements rapidly. The execution of this will be misrepresented to extra practical once contrast with the common framework.

Framework discovers that right reconfiguration of the Medical assets will build up the execution of the framework and conjointly beyond any doubt patness to the patients. The usage of the medicinal assets ought to be utilized appropriately. Upheld the arranging of framework is powerful and might encourage to the sensible medications framework by creating the solution. Framework discovers that right reconfiguration of the Medical assets will build up the execution of the framework and conjointly beyond any doubt patness to the patients. The usage of the medicinal assets ought to be utilized appropriately. Upheld the arranging of framework is powerful and might encourage to the sensible medications framework by creating the solution. 


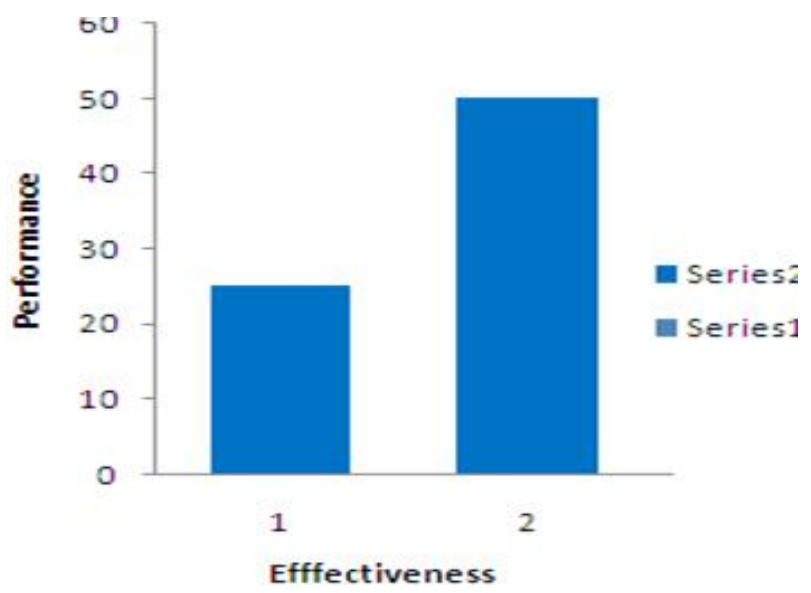

[Fig. 3] Existing System Performance

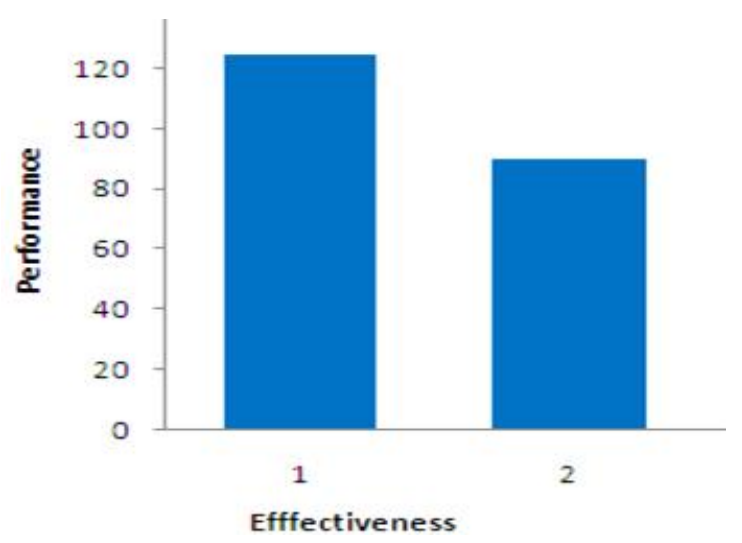

[Fig. 4] Proposed System Performance

By assessing the execution of the shrewd framework has been assessing the reconfiguration and the adequacy of delivering the patient treatment solution.

\section{Conclusion}

We finish IoT is that the all inclusive pervasiveness of things and articles that square measure met and square measure able to cooperate with each other to degree a standard objective. IoT degrees a pack of advancements that change an outsized differ of things to follow up on and impart among themselves abuse organizing data. A recovery framework is produced abuse IoT-based advances, SOA strategies, and multidisciplinary change techniques. Cosmology puts unsurpassed low for medical issue distinguishing proof and asset dissemination. In 
arranged, relate degree metaphysics based mechanizing vogue strategy for all time pharmaceutical and physical wellbeing framework misuse IoT innovation. This framework should be each powerful and sparing for the data sharing. 2 essential decisions, besides on the grounds that the short development of rebuilding framework thus the clear designation of space data, that got the opportunity to assemble the framework as unmistakable and perform excellent, as IoT and transcendentalism have battle an important part inside the technique.

\section{References}

[1] B. Nath, F. Reynolds, and R. Want, RFID Technology and Applications, IEEE Pervasive Computing (2006), Vol.5, No.1, pp.22-24.

[2] L. D. Xu, Enterprise Systems: State-of-the-Art and Future Trends, IEEE Transactions on Industrial Informatics (2011), Vol.7, No.4, pp.630-640.

[3] P. Elanthiraiyan and Dr. S. Babu, Smart Medicine and Physical Health System Using IoT, International Journal of Computer Science and Mobile Computing (2015), Vol.4, No.3, pp.333-338.

[4] M. Dohler, C. Ratti, J. Paraszczak and G. Falconer, Smart Cities [Guest Editorial], IEEE Communication Magazine (2013), Vol.51, No.6, pp.70-71.

[5] X. Li, R. Lu, X. Liang, X. Shen, and X. Lin, Smart Community: An Internet of Things Application, IEEE Communications Magazine (2011), Vol.49, No.11, pp.68-75.

[6] L. Atzori, A. Iera, and G. Morabito, The Internet of Things: A survey, Computer Networks (2010), Vol.54, No.28, pp.2787-2805.

[7] Y. Ding, Y. Jin, L. Ren, and K. Hao, An Intelligent Self-Organization Scheme for the Internet of Things, IEEE Computer Intelligence Magazine (2013), Vol.8, No.3, pp.41-53.

[8] M. A. Feki, F. Kawsar, M. Boussard, and L. Trappeniers, The Internet of Things: The Next Technological Revolution, Computer (2013), Vol.46, No.2, pp.24-25.

[9] C. Floerkemeier, C. Roduner, and M. Lampe, RFID Application Development With the Accada Middleware Platform, IEEE Systems Journal (2007), Vol.1, No.2, pp.82-94.

[10] W. He and L. D. Xu, Integration of Distributed Enterprise Applications: A Survey, IEEE Transactions on Industrial Informatics (2014), Vol.10, No.1, pp.35-42. 